\title{
Evaluation of the International Child Development Programme (ICDP) as a community-wide parenting programme
}

\section{Lorraine Sherr ${ }^{1}$, Ane-Marthe Solheim Skar ${ }^{2}$, Claudine Clucas ${ }^{1}$, Stephen von Tetzchner ${ }^{2}$, and Karsten Hundeide ${ }^{\dagger 2}$}

${ }^{1}$ Department of Infection \& Population Health, University College London, London, UK

${ }^{2}$ Department of Psychology, University of Oslo, Oslo, Norway

\begin{abstract}
Background: Many parenting programmes lack proper evaluation, especially under community-wide implementation. Objective: Examining the effectiveness of the eight-week International Child Development Programme (ICDP), implemented as a general programme. Methodology: Non-clinical caregivers attending ICDP $(N=141)$ and a non-attending community comparison group $(N=79)$ completed questionnaires on parenting, psychosocial functioning, and child difficulties before and after ICDP course. Analyses compare changes in scores for both groups over time. Results: The ICDP group showed more positive attitudes towards child management and reported better child management, improved parental strategies and less impact of child difficulties. Caregivers with low initial scores benefited most. The comparison group showed little change with a significant decrease in scores on the caregiver-child activity scale. Discussion: The results suggest that caregivers in the community who do not show clinical signs or have children with behaviour or other disorders, may benefit from participating in parent training based on ICDP.
\end{abstract}

Keywords: Early child development; Caregiver guidance; Community intervention; Evaluation; ICDP.

Correspondence should be addressed to Lorraine Sherr, UCL, Rowland Hill Street, London NW32PF, UK. Email: 1.sherr@ucl.ac.uk

The evaluation has been funded by the Norwegian Ministry for Children, Equality, and Social Inclusion.

The authors want to thank the Ministry and the Norwegian Directorate for Children, Youth and Family Affairs for their support and positive collaboration, and the ICDP facilitators and trainers, as well as the caregivers who gave of their time to the evaluation. Further thanks go to Trine Gerlyng, Ylva Snekkvik, Marit Reer, Hilde Breck, and Kristina Aas Fure for their assistance in data collection and registration.

${ }^{\dagger}$ This paper is written with posthumous credit to Professor Karsten Hundeide.

(C) 2013 The Author(s). Published by Taylor \& Francis.

This is an Open Access article distributed under the terms of the Creative Commons Attribution License (http://creativecommons.org/licenses/by/3.0), which permits unrestricted use, distribution, and reproduction in any medium, provided the original work is properly cited. The moral rights of the named author(s) have been asserted. 


\section{INTRODUCTION}

Throughout the history of child-care, there has been a focus on the importance of parent-child relations and early child development (von Tetzchner, 2012). In most societies, parents are the core of children's early social environment, and parenting strategies and parent-child relations are assumed to have an impact on all aspects of child development (Carlo, Mestre, Samper, Tur, \& Armenta, 2011; Landry, Smith, \& Swank, 2003; Sandler, Schoenfelder, Wolchik, \& Mackinnon, 2011). Interventions aimed at supporting parenting have mainly been directed at families at risk, such as socially disadvantaged families (e.g., Hutchings et al., 2007; McDonald, FitzRoy, Fuchs, Fooken, \& Klasen, 2012; Scott, O’Connor, et al., 2010) and those with clinical diagnoses (e.g., Law, Plunkett, Taylor, \& Gunning, 2009; Webster-Stratton, Kolpacoff, \& Hollingsworth, 1988). Boyd \& Gillham (2009) found more positive parent-child interactions and better coping skills in the children of depressed parents following intervention. Parents of children with attention-deficit hyperactivity disorder (ADHD) reported increased confidence and less stress after training (Anastopoulos, Shelton, DuPaul, \& Guevremont, 1993). Parental training is also found effective in reducing children's conduct problems (e.g., Ogden \& Hagen, 2008; Scott, Sylva, et al., 2010).

Challenges experienced in raising children are common and the positive results of parenting programmes with clinical groups may benefit a broader group of caregivers (Rodrigo, Almeida, Spiel, \& Koops, 2012) to improve all aspects of caregiving with possible onward benefits on child behaviour and caregiver mental health (Long, 2007; Sanders \& Morawska, 2010). One of the few efficacy studies of a generally implemented programme found increased positive and reduced negative parenting behaviour (Hahlweg, Heinrichs, Kuschel, Bertram, \& Naumann, 2010).

Yet there is a lack of efficacy research evidence (Rodrigo et al., 2012; Scott, 2010). In a review of 46 general and targeted interventions, Sandler et al. (2011) found long-term effects of parenting interventions on child development and behaviour, but a lack of explanation of the processes mediating these effects. The effects of programmes designed for specific clinical groups may be easier to explain but may not apply to caregivers with more ordinary challenges.

In order to develop optimal programmes for community-wide implementation, there is a need to investigate programmes based on different theoretical foundations and which comprise a variety of elements. Theoretically, most current parenting programmes are based on social learning theory and behaviour change, e.g., The Incredible Years (Webster-Stratton et al., 1988), Parental Management Training (Patterson, 2002) and the Triple P-programme (Sanders, 2008). Few evaluations are conducted in community settings (Hutchings et al., 2011). ICDP is a non-instructive psychosocial intervention programme directed 
towards parents and other caregivers. The programme is well recognized and is used in about 35 countries, including both socially well-functioning societies and societies where political unrest and war may make parenting especially challenging, and in collaboration with organizations such as Save the Children, Unicef, Care, and WHO. However, there is no evaluation of ICDP implemented as a community-wide programme in a socially well-functioning society. The present study examined the impact of ICDP courses on a general community sample of caregivers in Norway. The main research question was whether participation in an ICDP course would have a positive impact on parenting strategies and on how caregivers perceived their children and themselves. The moderating effects of self-efficacy, depression and social support were also investigated.

\section{METHOD}

The study used a two-group design with a natural intervention group $(N=141)$ and a comparison group $(N=79)$ who both completed questionnaires before and after the intervention group's ICDP course.

\section{The ICDP programme: Content and implementation}

The theoretical foundation of ICDP is derived from developmental and humanistic psychology with focus on sensitive adult adjustment and empathy (Hundeide \& Rye, 2010). It is non-instructive and aims to guide carers' understanding of their children and interaction with them. The philosophy is formulated in three dialogues containing eight guidelines: the emotional dialogue (e.g., showing loving feelings, praising and acknowledging the child), the comprehension dialogue (e.g., supporting the child's meaning-making and showing enthusiasm for the child's experiences), and the regulative dialogue (e. g., regulating the child's actions step-by-step; Hundeide, 2001; see http://icdp. info for details on ICDP).

ICDP courses are offered nationally in Norway by the Ministry of Children, Equality and Social Inclusion through "The Parental Guidance Programme". A filter-down approach is applied where the facilitators become qualified to run caregiver groups, and some facilitators proceed to become qualified to train new facilitators. Mothers and fathers of children at all ages may participate, but ICDP groups tend to contain parents with children in the pre-school age, and are usually delivered through ICDP educated staff at kindergartens and child health centres. The groups usually consist of 5-10 caregivers attending eight weekly two-hour sessions, one meeting for each guideline. Caregivers take an active role, participate in group discussions, role play the guidelines, and do home assignments, like "Try to follow your child's lead. What happens?" The 


\section{SHERR ET AL.}

facilitators give positive comments, encourage active involvement and facilitate discussions. Further details at http://www.bufetat.no/foreldrerettleiing/.

\section{Participants}

All ICDP facilitators were contacted and logged forthcoming groups for potential inclusion (Sherr, Skar, Clucas, von Tetzchner, \& Hundeide, 2009). A total of 75 ICDP groups were approached during the data collection period. The groups were run at kindergartens and health centres with carers recruited through open billboard information, staff advertisement or invitation. At the first meeting, caregivers were informed about the project verbally and in writing.

A group of 269 caregivers completed the first set of questionnaires and 141 (52.4\%) completed follow-up questionnaires. A comparison group $(N=157)$ to control for passage of time was recruited from child health centres and kindergartens in areas where the ICDP programme was not implemented, of whom $79(50.3 \%)$ returned the second questionnaire. The data were collected from October 2008 to March 2010. The ICDP caregivers had an average age of 36.6 (range 23-60), 2.0 children (range 1-6) and 3.6 people in the home (range $1-6)$. The focus child was 4.0 years on average $(S D=2.64$, range $0.5-16)$, 66 girls and 59 boys (16 caregivers did not provide information about gender). Caregivers in the comparison group had an average age of $34.2(S D=1.83$, range $24-47$ ). They had an average of 1.8 children (range $1-4$ ) and 3.5 people in the home (range $1-6)$. The focus child was 3.3 years $(S D=1.83$, range $0.25-$ 11), 35 were girls and 26 boys (18 caregivers did not provide information about gender). Caregivers in the two groups did not differ significantly on these variables. Caregivers in the comparison group were significantly more likely to be married or live with a partner and to have higher education than the ICDP group but the groups did not differ on gender, being born in Norway or employment (see Table 1).

\section{Materials}

All participants completed a questionnaire designed to gather information about demographics, social relationships, and emotional and parenting issues. Measures include self-efficacy, depression, social support, parenting (activities with the child, discipline, household commotion, happiness with partner, parenting strategy, engagement with the child and child management). Child measures include the Strengths and Difficulties questionnaire (see Table 2).

\section{Procedure}

Caregivers completed the questionnaires at the first meeting. They were asked to complete a second questionnaire after the last group meeting or returned it by mail. 
TABLE 1

Characteristics of caregivers in the ICDP group and the comparison group

\begin{tabular}{llrrrr}
\hline $\begin{array}{l}\text { Categorical } \\
\text { variables }\end{array}$ & & $\begin{array}{l}\text { ICDP } \\
(\%)\end{array}$ & $\begin{array}{l}\text { Comparison } \\
(\%)\end{array}$ & $\chi^{2}$ & $p$ \\
\hline Gender & Males & 25.5 & 21.5 & 0.38 & .536 \\
& Females & 74.5 & 77.2 & & \\
Education & Higher education & 58.9 & 74.7 & 5.34 & $.019 *$ \\
& No higher education (high school & 41.1 & 25.3 & & \\
Born in Norway & or less or other after high school) & & & & \\
& Yes & 90.8 & 89.9 & 0.004 & .952 \\
Civil status & No & 9.2 & 8.9 & & \\
& Married/partner & 89.4 & 94.9 & 3.99 & $.042 *$ \\
Employment & Separated/divorced/widow/single & 9.9 & 2.5 & & \\
& Full time & 55.3 & 70.9 & 5.59 & .061 \\
& Part time & 15.6 & 8.9 & & \\
& Other (e.g., at home or on leave) & 26.9 & 17.7 & & \\
\hline
\end{tabular}

Notes: $\operatorname{ICDP} N=141 ;$ Comparison $N=79 . * p<.05$.

Caregivers in the comparison group received the first questionnaires at time of consent and the follow-up questionnaire by mail after the same number of weeks as the ICDP group. If the questionnaire was not returned, one reminder was sent.

\section{Plan of analyses}

Chi-squared tests and $t$-tests were used to compare the groups on demographic variables, and to compare those lost to follow-up on demographic variables and scale scores to examine factors associated with no follow-up. As a result of differences between the ICDP group and the comparison in education, the study used 2 (Group: ICDP/comparison) $\times 2$ (Education: higher education/not higher education) $\times 2$ (Time of Measurement: before/after) mixed analysis of variance (ANOVA) with repeated measures on time of measurement. Interactions between Group and Time of Measurement are reported as these indicate differential changes for the intervention group and the comparison group and suggest an effect of the intervention on the outcome. Civil status differed between the groups but it was not possible to enter this factor in the main analysis because of the small number of caregivers who were not married or with a partner.

Two 2 (Group: ICDP/comparison) $\times 2$ (Education: higher education/not higher education) $\times 2$ (Time of Measurement: before/after) multivariate analyses of variance (MANOVAs) were used to study the effect of the intervention on the SDQ subscales (SDQ total difficulties and SDQ prosocial) and the subscales of the engagement scale (emotional engagement and strategic engagement). 


\section{SHERR ET AL.}

TABLE 2

Study measurements

Measure
Activities with the child:
The Parent-Child Activity
Scale (Bigner, 1977)
Positive discipline:
Conflict Tactics Scale
(Straus, 1979)

Household commotion:
The Confusion, Hubbub, and
Order Scale (Matheny
et al., 1995)

Parenting strategy:

Child management:

Engagement with the child:
Twenty-five items scored on a Likert scale 1 (Never) to 5 (Always), total scores ranging from 25 to 125 . Cronbach's $(\alpha=.88$ at first and .92 at second completion

Seven items on positive discipline created, e.g., "Praised them for achieving something on their own" and "Told them that you were proud of them". Caregivers indicated how frequently they engaged in the behaviours $(0,1-2,3-10$ or more than 10 times). A summed score was created by adding midpoints for the response categories, ranging from 0 to 105 . Cronbach's $(\alpha=.68$ at first and .37 at second completion. (The full Conflict Tactics Scale was used, but the results for the other subscales are not reported due to poor inter-item reliability; Cronbach's $(<.5)$

Fifteen items, which are scored as true or false, with summed scores ranging from 0 to 15 . A higher score represents a more chaotic, disorganized and hurried household. Cronbach's $(\alpha=.73$ at first and .73 at second completion

"Parenting strategies" measured the parental strategies with a focus on the comprehensive dialogue in the ICDP components. The five items loaded on one factor at first completion. The summed score for "Parenting strategies" ranged from 5 to $30(\alpha=.72$ at first and .76 at second completion). Negatively phrased items were reverse coded such that a higher score was always better

"Child Management" measured child management strategies with a focus on the emotional and regulative dialogue in the ICDP. The scale consists of 22 items scored on a Likert scale from 1 (Agree completely) to 5 (Completely disagree). Average scores range from 1 to 5 ( $\alpha=.77$ at first and .69 at second completion). Negatively phrased items reverse coded, so a lower score was always better

Ten bipolar items to measure key ICDP components, scored in counterbalanced order from 1 to 7 . Three scales were created: "engagement scale" eight items (e.g., sensitive-insensitive), loading on one factor at first completion in a principal components analysis (PCA); "emotional engagement scale" six items (e.g., loving-unloving), loading on one factor at second completion, and a "strategic engagement scale" three items (e.g., rewarding-punitive), loading on one factor at second completion. One item (strict-lenient) did not load on any of the two factors at second completion. Three mean scores generate dranging from 1 to 7 . For "engagement scale" Cronbach's 
TABLE 2 - continued

\begin{tabular}{|c|c|}
\hline Measure & Detail \\
\hline & $\begin{array}{l}\text { ( } \alpha=.86 \text { at first and } .84 \text { at second completion; for "strategic } \\
\text { engagement scale" }(\alpha=.72 \text { at first and } .76 \text { at second completion; } \\
\text { and for "emotional engagement scale" }(\alpha=.84 \text { at first and } .81 \text { at } \\
\text { second completion. A lower score indicates greater engagement }\end{array}$ \\
\hline \multicolumn{2}{|l|}{ Happiness with partner: } \\
\hline $\begin{array}{l}\text { Drawn from the Dyadic } \\
\text { Adjustment Scale (Spanier, } \\
\text { 1976) }\end{array}$ & $\begin{array}{l}\text { A visual analogue scale scored from } 0 \text { (Extremely unhappy) to } 6 \\
\text { (Perfectly happy) was utilized }\end{array}$ \\
\hline \multicolumn{2}{|l|}{$\begin{array}{l}\text { Strength and Difficulties } \\
\quad \text { Questionnaire: }\end{array}$} \\
\hline (SDQ; Goodman, 1999) & $\begin{array}{l}\text { Five subscales (emotional symptoms, conduct problems, } \\
\text { hyperactivity, peer problems, prosocial) generating three scores } \\
\text { (1) total difficulties ( } 0 \text { to } 40 ;(\alpha=.73 \text { at first and } .74 \text { at second } \\
\text { completion), (2) prosocial scale score ( } 0 \text { to } 10 ;(\alpha=.75 \text { at first } \\
\text { and } .80 \text { at second completion), and (3) an impact score derived } \\
\text { from questions on overall distress and social impairment ranging } \\
\text { from } 0 \text { to } 10\end{array}$ \\
\hline \multicolumn{2}{|l|}{ Depression: } \\
\hline $\begin{array}{l}\text { The Hospital Anxiety and } \\
\text { Depression Scale (HADS; } \\
\text { Zigmond \& Snaith, 1983) }\end{array}$ & $\begin{array}{l}\text { Consists of seven anxiety and seven depression items, which are } \\
\text { scored from } 0 \text { (Not at all) to } 3 \text { (Very often, most of the time, } \\
\text { definitely, very much), giving a summed score for depression } \\
\text { ranging from } 0 \text { to } 21 \text { ( } \alpha=.69 \text { at first completion) }\end{array}$ \\
\hline \multicolumn{2}{|l|}{ Social support: } \\
\hline $\begin{array}{l}\text { The Social Support } \\
\text { Questionnaire - Short } \\
\text { Form (SSQ6; Sarason et al., } \\
\text { 1987) }\end{array}$ & $\begin{array}{l}\text { Two scores were generated from this scale: a total number of social } \\
\text { supports score ranging from } 0 \text { to } 9(\alpha=.93 \text { at first completion) } \\
\text { and a satisfaction with social supports score ranging from } 1 \text { to } 6 \\
(\alpha=.91 \text { at first completion) }\end{array}$ \\
\hline
\end{tabular}

In order to study whether the intervention had a differential effect according to carer self-efficacy, depression or social support, moderation analyses were conducted. A median split was used to categorize carers into low and high selfefficacy, low and high depression and low and high satisfaction with social support. This factor was added to the 2 (Group: ICDP/comparison) $\times 2$ (Education: higher education/not higher education) $\times 2$ (Time of Measurement: before/after) mixed ANOVA (or MANOVA).

\section{Ethical considerations}

The study was approved by the Regional Committee for Medical and Health Research Ethics and the Norwegian Social Science Data Services. Therapist referral was available but no participants expressed a need for such a contact. 


\section{RESULTS}

\section{Attendance}

In the ICDP group, 96 caregivers $(68.1 \%)$ reported being offered eight meetings and 31 (21.9) were offered another number of meetings (14 missing). Forty-eight $(34.0 \%)$ attended all meetings held, 37 (26.2\%) missed one meeting, 22 (15.6\%) missed two meetings and $13(9.2 \%)$ missed more than two meetings (21 missing). Linear regression analyses showed no significant relationship between the number of sessions attended and change scores between first and second completion of questionnaires, when adjusting and when not adjusting for the number of meetings held.

\section{Follow-up}

Compared to the initial ICDP group, participants who completed the post questionnaires were more likely to be married/cohabiting (90\% vs. $79.8 \%), \chi^{2}(1$, $26)=5.40, p=.02$. They also reported significantly less depression $(M=3.18$, $S D=2.33$ ) than participants who did not complete the questionnaire after the course $(M=3.86, S D=2.84), t(1,25)=-2.09, p=.04)$. Compared to the initial group, participants in the comparison group who completed the second set of questionnaires were less likely to have a computer in the child's room $(0 \%$ vs. $6.6 \%), \chi^{2}(1,155)=5.37, p=.02$.

\section{Parental behaviours and impact of child difficulties}

Table 3 shows key variables for ICDP and comparison groups before and after the ICDP course. There was a significant interaction between Group and Time for parenting strategies, indicating that ICDP attendees improved their parenting strategies $(M=22.67$ and 23.52), while the comparison group did not change or had slightly lower scores $(M=23.54$ and 23.30). Follow-up analyses confirmed a significant improvement in the ICDP group on parenting strategies scale, $F(1$, $117)=25.28, p<.001, \eta_{\mathrm{p}}^{2}=.180$.

There was a significant interaction between Group and Time for amount of activity, indicating no change in amount of activity for the ICDP group $(M=101.80$ and 101.92), and a decrease in activity in the comparison group $(M=101.95$ and 98.81$)$. Follow-up analyses confirmed a significant decline in amount of activity in the comparison group, $F(1,43)=11.07, p=.002$, $\eta_{\mathrm{p}}^{2}=.213$.

A significant interaction between Group and Time of measurement for child management reflects that ICDP caregivers reported more positive attitudes and better child management after the course $(M=1.91$ and 1.79$)$, while there was no change in the comparison group $(M=1.82$ and 1.83). Follow-up analyses 
EVALUATION OF A COMMUNITY PARENTAL PROGRAMME 9

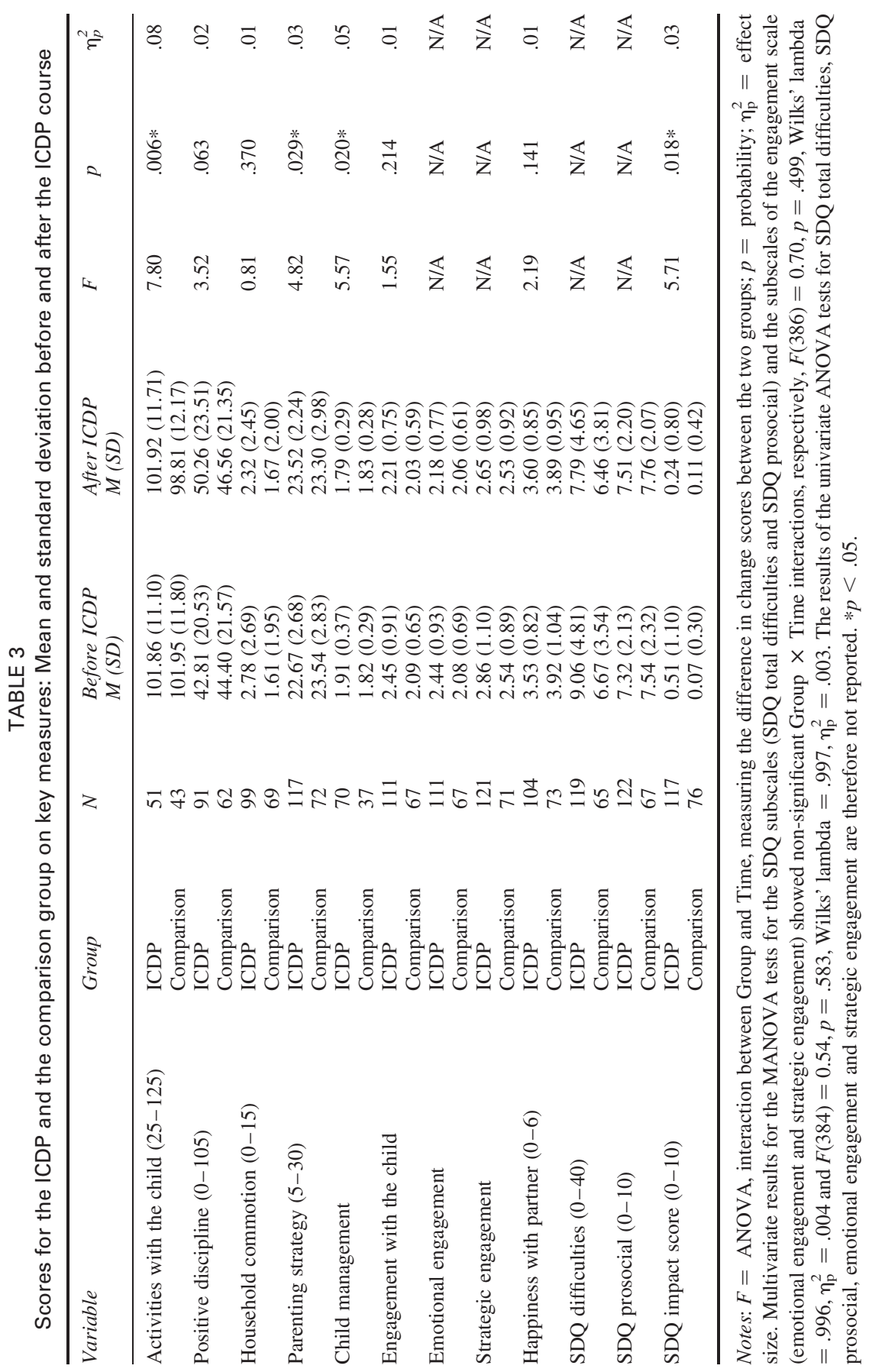


confirmed a significant improvement in the ICDP group on the child management scale, $F(1,70)=11.94, p=.001, \eta_{\mathrm{p}}^{2}=.149$.

Table 3 shows a significant interaction between Group and Time of measurement in the SDQ impact score, reflecting a decrease in parental reported overall distress and social impairment resulting from child difficulties in the ICDP group $(M=0.51$ and 0.24$)$, but not in the comparison group $(M=0.07$ and 0.11). Follow-up analyses confirmed a significant improvement in reported overall distress and social impairment in the ICDP group, $F(1,117)=8.06$, $p=.005, \eta_{\mathrm{p}}^{2}=.065$.

\section{Initial scores as moderators of ICDP effects}

Table 4 shows a significant three-way interaction between Group, Education and Time of measurement for household commotion. Caregivers with a higher education in the ICDP group showed a larger change in scores $(M=3.21$ and 2.50) on the Confusion, Hubbub, and Order Scale than the other groups (for caregivers with a higher education in the comparison group, $M=1.24$ and 1.49; and for caregivers without a higher education, $M=2.17$ and 2.07 in the ICDP group, and $M=2.81$ and 2.25 for the comparison group). Follow-up analyses confirmed a significant interaction between Group and Time of measurement for participants with a higher education but not for participants with a lower education for commotion in the household, $F(1,111)=11.32, p=.001$, $\eta_{\mathrm{p}}^{2}=.094$.

Table 4 shows a significant three-way interaction between HADS (low/high), Group and Time for child management. For caregivers with low depression scores, $M=1.82$ and 1.73 in the ICDP group, and 1.85 and 1.80 in the comparison group. For caregivers with high depression scores, $M=1.99$ and 1.84 in the ICDP group, and 1.81 and 1.86 in the comparison group. The results indicate that participation in the ICDP course may have a greater effect on caregivers with higher depression scores. Follow-up analyses to further investigate this three-way interaction showed a significant interaction between Group and Time of measurement for parents with higher depression scores, $F(1$, $58)=8.59, p=.005, \eta_{\mathrm{p}}^{2}=.137$, but not for parents with lower depression scores. Several three-way interactions approached significance with a similar pattern. For parenting strategy, for caregivers with low depression scores, $M=23.66$ and 24.16 for the ICDP group, and 24.14 and 24.11 in the comparison group. For caregivers with high depression scores, $M=21.95$ and 23.06 in the ICDP group, and 22.97 and 22.54 in the comparison group $(F=2.80, p=.096$, $\left.\eta_{\mathrm{p}}^{2}=.015\right)$. With regard to commotion in the home, for caregivers with low depression scores, $M=2.11$ and 1.66 in the ICDP group, and 1.44 and 1.11 in the comparison group. For caregivers with high depression scores, $M=3.37$ and 2.91 in the ICDP group, and 1.79 and 2.27 in the comparison group $(F=3.20$, $\left.p=.076, \eta_{\mathrm{p}}^{2}=.020\right)$. Three-way interactions between depression, group and 


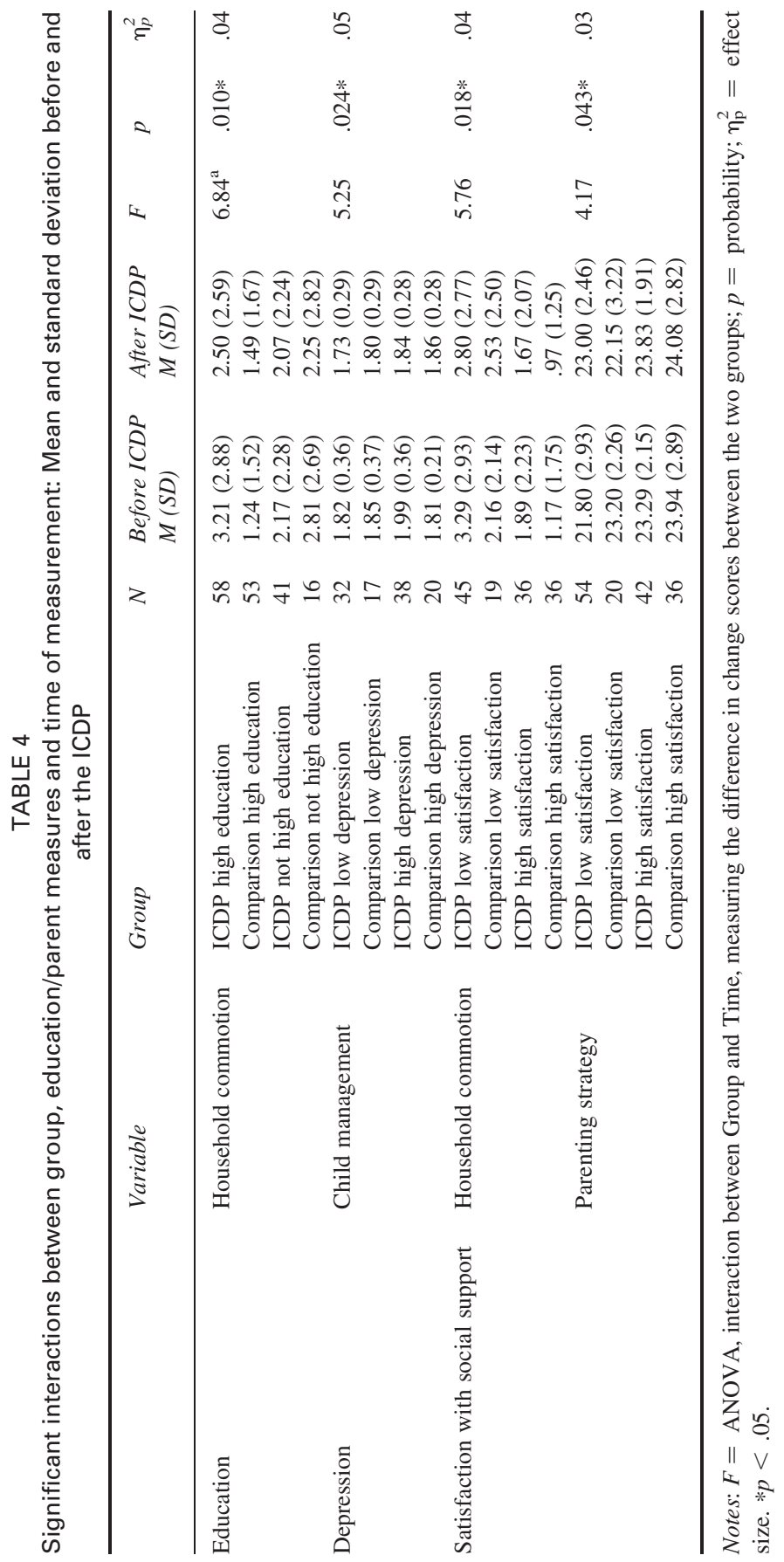


time on positive discipline, activities, engagement (strategic or emotional), and child difficulties were not significant.

There were significant three-way interactions between satisfaction with social support (low/high), group and time for parenting strategy and commotion in the home. With regard to parenting strategy, for caregivers with low satisfaction scores, $M=21.80$ and 23.00 in the ICDP group, and 23.20 and 22.15 in the comparison group. For caregivers with high satisfaction scores, $M=23.29$ and 23.83 in the ICDP group, and 23.94 and 24.08 in the comparison group. For commotion in the home, for caregivers with low satisfaction scores, $M=3.29$ and 2.80 in the ICDP group, and 2.16 and 2.53 in the comparison group. For caregivers with high satisfaction scores, $M=1.89$ and 1.67 in the ICDP group, and 1.17 and 0.97 in the comparison group. The results indicate that participating in ICDP had a more positive influence on parenting strategies and family commodity for participants who were less satisfied with their social support. Follow-up analyses showed a significant interaction between Group and Time of measurement for participants with lower satisfaction with their social support but not for participants with higher satisfaction with their social support for parenting strategy, $F(1$, $74)=7.19, p=.01, \eta_{\mathrm{p}}^{2}=.093$, and home commotion, $F(1,64)=4.23, p=.044$, $\eta_{\mathrm{p}}^{2}=.066$. There was a three-way interaction approaching significance for child management. For caregivers with low satisfaction scores, $M=2.08$ and 1.87 in the ICDP group, and 1.88 and 1.91 in the comparison group. For caregivers with high satisfaction scores $M=1.81$ and 1.72 in the ICDP group, and 1.77 and 1.74 in the comparison group $\left(F=2.86, p=.095, \eta_{\mathrm{p}}^{2}=.035\right)$. This indicates that participating in ICDP had a more positive influence on child management for caregivers who were less satisfied with their social support. Thus quality, not quantity, of social support mattered. There was no significant interaction with number of social supports. There were no three-way interactions between social support, group and time on positive discipline, activities, engagement (strategic or emotional), and child difficulties, or between scores on the Generalized SelfEfficacy Scale (low/high), group and time of measurement for measures of positive discipline, activities, engagement (strategic or emotional), parenting strategy, child management, commotion in the home and child difficulties.

\section{DISCUSSION}

The results suggest that the ICDP may be effective in promoting positive parenting in a general community sample. There were a consistent number of positive and significant effects of the programme including parenting strategies and attitudes towards child management and perceived ability to manage the child, and social impairment resulting from child difficulties. The lack of similar changes in the comparison group indicates that the results cannot be explained by the passage of time. Several measures converged, suggesting that ICDP also may have a positive effect on the caregivers' evaluation of child difficulties, use of 
positive discipline, and engagement with the child, but these trends were not significant in the interaction analysis. The comparison group scored lower on activities with the child at follow-up, whereas the ICDP group did not change. Participation in the study resulted in increased awareness of parenting influences among the participants. Both groups may have become more concerned about their parenting but only the caregivers in the comparison group scored lower because they did not receive the support that the ICDP group benefited from through the course. Another hypothesis is that participation in the ICDP course prevented some of the usual stressors on family life that may imply fewer caregiver-child interactions.

It is noteworthy that participants with low initial scores in particular seemed to benefit from participation in the programme. Caregivers may have different reasons for taking part in the programme. Some caregivers may look for a parenting programme because they are struggling with everyday child rearing and are lacking useful strategies, because it has been suggested by a friend or a teacher in the kindergarten, or they may be referred to the programme by social services. The fact that there were more single parents in the ICDP group may reflect the increased strain of childrearing with one rather than two parents. Other studies of parenting programmes also report a relatively large proportion of single parents (Almeida et al., 2012). It is in line with the aims of the programme that parents who seem to struggle most, show the greatest positive change. Other caregivers might have good self-confidence and experience few problems with their children, and attend the programme because they want all the knowledge they can get. This group shows less change because participation in the programme is consolidating their existing attitudes and use of strategies rather than initiating change.

One result of the broad focus of the ICDP approach is differential effect on various subgroups. There was a decrease in commotion in the home following ICDP participation but this was only significant for caregivers with higher education. Other studies of parenting programmes have also found that parents with lower education may benefit less than more educated parents (Almeida et al., 2012; Fossum, Drugli, Handegård, \& Mørch, 2010), but in this study the moderating effect of education applied only to this domain. Participation in the programme seemed to lead to a larger positive change in attitudes towards child management and perceived ability to manage the child in caregivers with relatively higher depression scores on HADS. Caregivers who expressed less satisfaction with the social support they received showed greater improvement in parenting strategies and lower commotion in the home than caregivers who were more satisfied with their social support. Several studies of parenting programmes have focused on caregivers who are clinically depressed or at severe social risk (Boyd \& Gillham, 2009; Law, Plunkett, Taylor, \& Gunning, 2009). A community-wide programme may contribute to positive parenting in mothers and fathers with subclinical depression who are not usually referred to the mental health services. Several authors have pointed to a need for generally available 


\section{4}

parenting programmes (Sanders \& Morawska, 2010; Shapiro, Prinz, \& Sanders, 2008) such as this programme, which appears to reach caregivers in need of support and advice who may experience the task of raising children as manageable but challenging, but have no diagnosis or clear clinical challenge.

There are some limitations with the present study. All children in both groups were of preschool age, yet there was a variation in the ages. There were insufficient subgroups to break down the results by age, but this may be an important factor in subsequent studies. Another limitation was the fact that there were some significant differences between the ICDP and comparison group at baseline and hence they do not necessarily represent the same population. The comparison group was recruited from health centres and kindergartens where ICDP courses were not available, while the ICDP group seems to have made some self-initiated or other-initiated efforts to follow the programme. This means that the ICDP group to some extent might have been biased and have had more motivation and potential for change than the comparison group. However, this is not only a weakness. Most evaluations are of programmes implemented by research institutions (Rodrigo et al., 2012). The present study gives evidence that ICDP (or other general parenting programmes) may reach the group it is aiming at and function in community-wide implementation. Other limitations are attendance and loss to follow-up by approximately half of the participants, which may have skewed the results for successful participants; those with more time, support or less depression being overrepresented at follow-up. Baseline comparisons showed that those with partners and lower depression scores were more likely to respond. Question omission indicated by the variation in $\mathrm{N}$ may have resulted in reduced numbers and diminished power. Finally, caution should also be exerted as a result of the multiple F-tests conducted (Bakan, 1969) and self-reported measures.

A pre-investigation was conducted to address the quality of implementation, and the relationship between number of meetings attended and change scores was addressed. Future investigations should address the relationship between implementation quality and programme effects more specifically. There is still a lack of knowledge about mediating processes and the interaction between programme features and child and parent characteristics (Deković, Stoltz, Schuiringa, Manders, \& Asscher, 2012; Law et al., 2009). Some programme features may benefit most caregivers while other features may be beneficial for parents and children with particular characteristics, even if clinical groups are excluded. Mechanisms accounting for change are not fully understood and may include group conversation, regulation without strict control or new skills. A larger randomized controlled trial could shed more light on this, as would additional observations (Davé, Nazareth, Senior, \& Sherr, 2008), and longer term outcomes (Sandler et al., 2011).

The results of this and other studies indicate that caregivers may benefit from participating in parenting programmes, including caregivers (and children) without clinical conditions. The results support the call for community-wide 
implementations of ICDP and other parenting programmes in spite of the heterogeneous nature of the population (Rodrigo et al., 2012). The basic philosophy of ICDP, with a focus on positive emotion and regulation, rather than on control, which is more apparent in parenting programmes for parents who have children with behaviour disorders, may resonate well in many parents who experience the ordinary challenges of everyday child-rearing, and who may not need or feel comfortable with a more controlling approach.

Manuscript received 31 May 2012

Revised manuscript accepted 3 April 2013

First published online 10 May 2013

\section{REFERENCES}

Almeida, A., Abreu-Lima, I., Cruz, O., Gaspar, M. F., Brandao, T., Alarcao, M., ... Machado, J. (2012). Parent education interventions: Results from a national study in Portugal. European Journal of Developmental Psychology, 9, 135-149.

Anastopoulos, A., Shelton, T., DuPaul, G., \& Guevremont, D. (1993). Parent training for attention deficit hyperactivity disorder: Its impact on child and parent functioning. Journal of Abnormal Child Psychology, 21, 581-596.

Bakan, D. (1969). On method. San Francisco: Jossey-Bass.

Bigner, J. J. (1977). Attitudes toward fathering and father-child activity. Home Economics Research Journal, 6, 98-106.

Boyd, R. C., \& Gillham, J. E. (2009). Review of interventions for parental depression from toddlerhood to adolescence. Current Psychiatry Review, 5, 226-235.

Carlo, G., Mestre, M. V., Samper, P., Tur, A., \& Armenta, B. E. (2011). The longitudinal relations among dimensions of parenting styles, sympathy, prosocial moral reasoning and prosocial behaviors. International Journal of Behavioral Development, 35, 116-124.

Davé, S., Nazareth, I., Senior, R., \& Sherr, L. (2008). A comparison of father and mother report of child behaviour on the Strengths and Difficulties Questionnaire. Child Psychiatry and Human Development, 39, 399-413.

Deković, M., Stoltz, S., Schuiringa, H., Manders, W., \& Asscher, J. J. (2012). Testing theories through evaluation research: Conceptual and methodological issues embedded in evaluations of parenting programmes. European Journal of Developmental Psychology, 9, 61-74.

Fossum, S., Drugli, M. B., Handegård, B. H., \& Mørch, W. -T. (2010). Barns aggressive atferdetter foreldretrening [Children's aggressive behaviour after parent training]. Tidsskrift for Norsk Psykologforening, 47, 1020-1025.

Goodman, R. (1999). The extended version of the strengths and difficulties questionnaire as a guide to child psychiatric caseness and consequent burden. Journal of Child Psychology and Psychiatry, 40, $791-799$.

Hahlweg, K., Heinrichs, N., Kuschel, A., Bertram, H., \& Naumann, S. (2010). Long-term outcome of a randomized controlled universal prevention trial through a positive parenting programme: Is it worth the effort? Child and Adolescent Psychiatry and Mental Health, 4, 1-14.

Hundeide, K. (2001). Ledet samspill fra spedbarn til skolealder. Håndbok til ICDPs sensitiviseringsprogram [Guided interaction from infancy to school age. Handbook to ICDP's sensitivity programme]. Oslo: Vett og Viten.

Hundeide, K., \& Rye, H. (2010). The early history, development and basic values of ICDP. Paper presented at ICDP conference, Denmark. (Available at: http://www.icdp.info/Earlyhistory.pdf). 


\section{6}

SHERR ET AL.

Hutchings, J., Bywater, T., Daley, D., Gardner, F., Whitaker, C., Jones, K., . . Edwards, R. T. (2007). Parenting intervention in Sure Start services for children at risk of developing conduct disorder: Pragmatic randomised controlled trial. British Medical Journal, 334(7595), 678-682.

Hutchings, J., Bywater, T., Williams, M. E., Whitaker, C., Lane, E., \& Shakespeare, K. (2011). The extended school aged Incredible Years Parent Programme. Child and Adolescent Mental Health, $16,136-143$.

Landry, S. H., Smith, K. E., \& Swank, P. R. (2003). The importance of parenting during early childhood for school-age development. Developmental Neuropsychology, 24, 559-591.

Law, J., Plunkett, C., Taylor, J., \& Gunning, M. (2009). Developing policy in the provision of parenting programmes: Integrating a review of reviews with the perspectives of both parents and professionals. Child: Care, Health and Development, 35, 302-312.

Long, N. (2007). Learning from experience: Shifting from clinical parent training to broader parent education. Clinical Child Psychology and Psychiatry, 12, 385-392.

Matheny, A. P., Wachs, T. D., Ludwig, J. L., \& Phillips, K. (1995). Bringing order out of chaos: Psychometric characteristics of the Confusion, Hubbub, and Order Scale. Journal of Applied Developmental Psychology, 16, 429-444.

McDonald, L., FitzRoy, S., Fuchs, I., Fooken, I., \& Klasen, H. (2012). Strategies for high retention rates of low-income families in FAST (Families and Schools Together): An evidence-based parenting programme in the USA, UK, Holland and Germany. European Journal of Developmental Psychology, 9, 75-88.

Ogden, T., \& Hagen, K. A. (2008). Treatment effectiveness of parent management training in Norway: A randomized controlled trial of children with conduct problems. Journal of Consulting and Clinical Psychology, 76, 607-621.

Patterson, G. R. (2002). Etiology and treatment of child and adolescent antisocial behaviour. The Behaviour Analyst Today, 3, 133-143.

Rodrigo, M. J., Almeida, A., Spiel, C., \& Koops, W. (2012). Introduction: Evidence-based parent education programmes to promote positive parenting. European Journal of Developmental Psychology, 9, 2-10.

Sanders, M. R. (2008). Triple P-positive parenting programme as a public health approach to strengthening parenting. Journal of Family Psychology, 22, 506-517.

Sanders, M. R., \& Morawska, A. (2010). Prevention: The role of early universal and targeted interventions. In R. C. Murrihy, A. D. Kidman \& T. H. Ollendick (Eds.), Clinical handbook of assessing and treating conduct problems in youth (pp. 435-454). New York, NY: Springer.

Sandler, I. N., Schoenfelder, E. N., Wolchik, S. A., \& Mackinnon, D. P. (2011). Long-term impact of prevention programmes to promote effective parenting: Lasting effects but uncertain processes. Annual Review of Psychology, 62, 299-329.

Sarason, I. G., Sarason, B. R., Shearin, E. N., \& Pierce, G. R. (1987). A brief measure of social support-Practical and theoretical implications. Journal of Social and Personal Relationships, 4, 497-510.

Scott, S. (2010). National dissemination of effective parenting programmes to improve child outcomes. British Journal of Psychiatry, 196, 1-3.

Scott, S., O’Connor, T. G., Futh, A., Matias, C., Price, J., \& Doolan, M. (2010). Impact of a parenting programme in a high-risk, multi-ethnic community: The PALS trial. Journal of Child Psychology and Psychiatry, 51, 1331-1341.

Scott, S., Sylva, K., Doolan, M., Price, J., Jacobs, B., Crook, C., \& Landau, S. (2010). Randomized controlled trial of parent groups for child antisocial behaviour targeting multiple risk factors: The SPOKES project. Journal of Child Psychology and Psychiatry, 51, 48-57.

Shapiro, C. J., Prinz, R. J., \& Sanders, M. R. (2008). Population-wide parenting intervention training: Initial feasibility. Journal of Child and Family Studies, 17, 457-466.

Sherr, L., Skar, A. -M. S., Clucas, C., von Tetzchner, S., \& Hundeide, K. (2009). Facilitator report. Oslo: ICDP International. 
Spanier, G. (1976). Measuring dyadic adjustment: Nine scales for assessing marriage and similar dyads. Journal of Marriage and the Family, 38, 15-28.

Straus, M. A. (1979). Measuring intrafamily conflict and violence: The Conflict Tactics (CT) Scales. Journal of Marriage and Family, 41(1), 75-88.

von Tetzchner, S. (2012). Utviklingspsykologi, Annen utgave [Developmental psychology, 2nd ed.]. Oslo: Gyldendal Akademisk.

Webster-Stratton, C., Kolpacoff, M., \& Hollingsworth, T. (1988). Self-administered videotape therapy for families with conduct-problem children. Journal of Consulting and Clinical Psychology, 56, 558-566.

Zigmond, A. S., \& Snaith, R. P. (1983). The Hospital Anxiety and Depression Scale. Acta Psychiatrica Scandinavica, 67, 361-370. 